\title{
ADHD and Learning Motivations
}

\author{
Eleni Ventouri \\ Special Educator MASEN-Occupation Therapist S. I., Paros, Greece \\ Email: ventourieleana@yahoo.gr
}

How to cite this paper: Ventouri, E. (2020) ADHD and Learning Motivations. Open Access Library Journal, 7: e6594. https://doi.org/10.4236/oalib.1106594

Received: July 8, 2020

Accepted: August 25, 2020

Published: August 28, 2020

Copyright $\odot 2020$ by author(s) and Open Access Library Inc.

This work is licensed under the Creative Commons Attribution International License (CC BY 4.0).

http://creativecommons.org/licenses/by/4.0/

\begin{abstract}
The purpose of this research was to investigate the learning motivations of a student with ADHD, through the views of all members of the interdisciplinary team as well as the parent of the student under study but also through the observation of the child himself. The present study followed the qualitative methodology of the case study and source triangulation, collecting data not only through semi-structured interviews by four interdisciplinary team experts working with a 9-year-old ADHD student, but also through closed-ended and unstructured closed-ended questionnaires. The study involved a 9-year-old student with a diagnosed ADHD who is also the subject of the observation, the special educator, the speech therapist, the occupational therapist, the psychologist working with the child and the child's mother. The results of the research showed that the knowledge of the participating specialists in relation to learning motivations is targeted and partially limited, in the sense that they mainly referred to the importance and necessity of using external motivations in the form of rewards and enhancers, without being done by anyone reference to the internal motivations and mechanisms through which the motivations contribute to the students with ADHD. Regarding the ways of strengthening the student's learning motivations with ADHD, the behavioral reinforcement model dominated, with the participants' reports being limited to the reward table, the child's interests, play and rewards in general. It is recommended to conduct interventional studies and experimental studies that will help in practice to try techniques and interventions that are not limited to the behavioral model of reinforcement, but also use elements from modern literature that supports the emphasis and internal motivations related to self-efficacy and self-portrait of children with ADHD.
\end{abstract}

\section{Subject Areas}

Education

\section{Keywords}

ADHD, Learning Motivations, Special Education and Training 


\section{Introduction}

ADHD, or "Attention-Deficit Hyperactivity Disorder" is one of the most common and diagnosed disorders in school-age children. It is a disorder that significantly affects students' behavior, resulting in significant learning difficulties. One area of interest in research on ADHD is learning motivation. Motivation is one of the key elements in ensuring the essential involvement of a student in educational processes, that is, that of mobilization through the adoption by the teacher of appropriate methods, which will produce motivations that are inextricably linked to the student's interests. Therefore, the study of learning motivations in students with ADHD is particularly important, in order to form more effective and appropriate pedagogical and educational interventions for the specific student population.

The purpose of this research is to investigate the learning motivations of a student with ADHD, through the views of all members of the interdisciplinary team as well as the parent of the student under study and through the observation of the child himself. So, the research questions of the proposed research are as follows:

- What do the teaching staff and the special educator know about learning motivations?

- How is the effort to develop student learning motivation with ADHD selfassessed?

- What factors are barriers to learning motivation?

- What actions are taken to develop learning motivations?

So, the current research is divided in some sub-categories so to be more understandable. To start with, the researcher gives some general characteristics both for ADHD and Learning Motivations. The methodology is next, with all the tools that were used in order to conduct the research, as well the issues of validity, reliability and Ethics. The research ends with the results and the conclusion.

\section{Attention Deficit Hyperactivity Disorder}

\subsection{Definition}

ADHD or "Attention Deficit Hyperactivity Disorder", is one of the most common and diagnosed disorders in school children, while according to the American Psychiatric Association, along with disorders such as "Disorder of Management" and "Antimotor Provocative Disorder", belongs to the subcategory of attention deficit disorder and disruptive behavior [1]. The case of ADHD is a disorder that can occur at birth and last for a lifetime. Some researchers report cases of children who have some of the symptoms of ADHD due to the presence of other types of problems, without necessarily having ADHD [2], while some other researchers consider ADHD to be inextricably related to the factors of emotional difficulties and difficulties in the behavior of the individual [3]. Overall, ADHD is a developmental disorder in which symptoms such as inattention and hyperactivity-impulsivity is present and which follow the person throughout life 
and can cause great and various difficulties to the child. suffering from it, but also in its wider environment [4].

It is also argued that children with ADHD are faced with a number of negative consequences, including the greatest number of failures, a sense of inadequacy in their abilities in most areas of their lives, and the failure to acquire social skills and acceptance. Therefore, they face intense difficulties in the context of their integration into the general classes, as they are faced with intense rejection by their peers, thus maintaining a small number of friendly ties [5].

ADHD can be divided into two types, primary and secondary. In the case of the former, the disorder occurs in childhood, with the causes being biological, which implies the absence of a specific cause of onset. Its duration exceeds the period of six months, while in most cases it follows the child throughout his/her life. The primary type can appear in any environment, while at the same time it can affect any interpersonal relationship that this person may develop. In the case of the second type, the onset of the disorder occurs more slowly and not in childhood. Its causes are external, as the person is influenced by factors that exist in his environment. The duration of the secondary type is shorter than the primary one, as it is most often presented for a period of less than six months. It basically occurs within specific environments, where a specific and temporary cause is presented. A typical example of a secondary attention deficit is the case of students who are unable to concentrate on a particular lesson, while in the rest they concentrate normally [3].

In the case of Greece, the definition of ADHD syndrome, even today, continues to be governed by ambiguity and controversy. More specifically, it is used as a term to describe and label children who have a strong problem with attention span, control of their impulsiveness, and control of their hyperactivity [6].

\subsection{Epidemiology of ADHD}

The occurrence of ADHD is a significantly rarer phenomenon than it is considered as, although, in a large number of children and especially boys, the characterization of the hyperactive, unable to sit quietly and unable to concentrate for a long time can be attributed, the case of the real clinical entity presupposes the existence of a specific number of coexisting difficulties. These difficulties may be found in $1 \%$ of children aged 11 and under, and are found in boys with almost three times the frequency compared to girls. Due to the improvement of physical hyperactivity over the years, there is still some ambiguity regarding the nature of these problems during adolescence and adulthood. Most likely, the remaining difficulties are largely related to the young people's ability to concentrate and the social maturity that characterizes them, although the latter is not among the diagnostic features. A percentage that ranges between $30 \%-50 \%$ of children with ADHD exhibit antagonistic behavior, forming a combination that is more difficult to deal with. Finally, ADHD tends to occur more frequently among people from lower social and economic groups, such as urban areas, although not all studies have confirmed this [5]. 


\subsection{Diagnosis of ADHD}

The American Psychiatric Association and the World Health Organization have established international standards for the diagnosis of ADHD, on the basis of which they largely constitute certain questionnaires. The American Psychiatric Association has categorized the diagnostic criteria into the following subcategories: the first category is the Attention Deficit Disorder, the second is Hyperactivity and Impulsivity, and the third is the "Combined Attention Deficit Hyperactivity Disorder [7]. This categorization results in the predominant type of distraction, where there is distraction without hyperactivity, the predominant type of hyperactivity, where there is hyperactivity without distraction and finally the type that combines the two aforementioned, where both hyperactivity and distraction are observed. On the other hand, the World Health Organization denies the existence of corresponding subcategories [6].

Between the specialists that can make the diagnosis of ADHD are included specialized psychologists, child psychiatrists, pediatric neurologists and developmental pediatricians. These experts make a subjective diagnosis, using mainly questionnaires, which are asked to be completed by either the child's parents or his/her teachers. This should be followed by a clinical evaluation by a specialist. The aforementioned subjectivity that governs the criteria used by the experts on a case-by-case basis makes the process of diagnosing ADHD less reliable. This is evidenced by the results of the international research of Dr. Lee in the year 2008, based on which the diagnoses made by the same experts on the same children are in agreement with each other only in $11 \%$ of cases [6].

The process of diagnosing ADHD is clinical and therefore in order for someone to make a diagnosis it is necessary to first have some suspicion about the existence of a clinical condition on the occasion of behavioral problems and then to clearly separate the environmental, cognitive and biological fields. At this point it should be mentioned that in order to diagnose a child with ADHD, it is necessary to show a series of symptoms, as the appearance of a symptom is an indication, which, however, does not necessarily prove the existence of ADHD. It should also be emphasized that there is an ambiguity as to whether ADHD is a form of disability, as this is inextricably linked to both the number of symptoms and their severity, and the environment in which the child lives. Within this combined framework, it is determined whether the case of a child with ADHD will be considered a weakness or a disability [8].

\subsection{Causes of ADHD}

There are a variety of causes that can lead a person to developing ADHD, which are divided into two major categories: organic causes and environmental causes. The first category of causes refers to pre-perinatal factors and more specifically to causes that are impossible to calculate and prevent by the individual, and which in turn have resulted in the onset of this disorder. Among the organic causes are the various brain damage and some kind of brain dysfunction, which may occur 
in the individual even in his fetal form. Other factors that can affect the human body in such a way as to cause the onset of ADHD are those of allergies and the diet chosen by a person [9].

In the second category, that of environmental causes include external causes and more specifically, factors that exist in a child's broad social environment and that have a direct impact on him/her. One of these reasons is that of psychosocial deprivation, as it has been observed that children living in psychosocially deprived environments, with typical examples of institutions and non-privileged social strata, tend to evolve more slowly in talking and speech, presenting low quality performance compared to the normal rate of progress. Another cause is the presence of some kind of psychopathological disorder in a parent, with a typical example being depression. A key factor is also the existence of a low economic and educational level in the family, because there is a direct impact on the overall development of the child's character, as well as on his educational and social level [9].

However, perhaps the most important factor that can lead to the occurrence of ADHD in a person is that of unimportant hereditary conditions. According to research, the hereditary factor in a percentage of $76 \%$ of cases, is responsible for the occurrence of ADHD. More specifically, almost $76 \%$ of people with ADHD have a relative who also has the disorder. It should be noted that in cases where one of the parents suffers from the disorder, there is a $57 \%$ chance that the children will also suffer. In addition, the rate of heredity in the case of twins is particularly high [8].

There are also some toxic factors that can lead to the disorder, as some mothers during pregnancy do not stop harmful habits such as smoking, alcohol consumption and the use of toxic substances. In these cases, children are twice as likely to develop ADHD symptoms. Finally, even the age of the mother when giving birth to a child may affect the occurrence or not of this disorder [8].

\subsection{ADHD Symptomatology}

As for the symptoms of Attention Deficit Hyperactivity Disorder, it is divided into two main parts: primary attention deficit disorder, spontaneous movement and hyperactivity disorder, and secondary symptoms, including school problems, which include difficulty in coping with failures which may be related to the existence of other learning difficulties, the small number of friends and social relationships and the low level of self-confidence [9].

In particular, the main characteristics of a student with ADHD include the following symptoms. Initially, there is intense anxiety and hyperactivity, as these children are unable to stay in the same place for a long time, as well as do the same activity. They tend to turn around nervously, talk constantly, and interrupt their interlocutor when he speaks. They are also characterized by easy distraction, and rarely complete a task. They usually have a limited range of attention, and have difficulty concentrating on tasks that require reflection. They are also 
characterized by particular impulsiveness, as they perform actions that they have not previously considered, while at the same time they find it difficult to expect their turn in all kinds of social and academic activities, inside and outside the classroom [9].

Most of the time, children with ADHD have normal mental ability, although it is possible that some children with learning disabilities may also have ADHD. They may also experience other types of difficulties, which are not typical in ADHD cases, so they are not diagnostic symptoms, which are secondary and can be caused by the aforementioned problems [10].

In addition, a child with ADHD may have a delay in the development of speech, as well as difficulties in reading. The above, combined with the inability to gather and assimilate new information of some students with ADHD, especially in the larger school classrooms, has the consequence that they lag behind their classmates in the speed of schoolwork. As mentioned above, another characteristic of children with ADHD is that of social immaturity and the difficulty of developing and maintaining friendships, but also social relationships as a whole. A determining factor in this is the low self-esteem and trust that children have for themselves, because they feel less capable and smart because of their different learning rhythms. Even these individuals, in several cases, have coexisting problematic problems, including aggression, disobedience, and outbursts of anger. Finally, they sometimes experience problems such as restless sleep and idiosyncratic sleep hours, with the result that not only children with ADHD but also the rest of their family are affected by it [10].

Of course, the observation of all the above symptoms should be done gradually, over a long period of time and through the prism of a variety of situations both at home and at school. Also, in order for the interpretation of these children's behaviors to be timely and valid, it is necessary to take into account the chronological and learning age of the children and compare them with the typical behaviors of children of the respective ages [11].

\subsection{Dealing with ADHD}

As a rule, the diagnosis of a child with ADHD is documented by a child psychiatrist, after taking into account the findings of the respective teachers and school psychologists. In some cases, pediatricians take part in the overall procedure. In the context of clinical evaluation, it is necessary to include both the history given by the parents and the observations made within the clinic and the school, due to the fact that a brief contact may be misleading and lead to erroneous conclusions. Therefore, a visit to the child's school is essential for the collection of information and the formation of a common plan of handling and intervention. Conducting neurological tests and further medical tests depends on the presence of neurological signs and whether the child is to be given medication. In order to effectively manage ADHD, it is possible to adopt educational and pharmacological treatments as well as behavioral therapies, among which there is no mutual exclusion and which of course are not necessary in all cases. 
Crucial to the treatment of ADHD are the factors of parents' perceptions and substantiated decisions and the effect that emerging deficits have on a person's life with ADHD [8].

Often children with ADHD are possessed by emotions such as weakness, insecurity, frustration and anger. Therefore, parents and their attitude must be governed by the elements of understanding, support, self-confidence and positivity towards their child, in order to lead the child to the formation of a positive self-perception. A child's self-awareness, self-control skills and self-esteem shape the system of the self. In this context, the self-esteem factor is inextricably linked to the parallel abilities of self-control and self-regulation, as a person who can control the parameters of his activities and emotional expressions, feels more capable. Then a child who succeeds in transforming his behavior into a socially acceptable and appropriate one is more likely to receive positive judgment and approval from others [12] [13].

In the school environment, these children should be able to consult a school psychologist, and in order to make the strategy of dealing with ADHD more effective, it is a prerequisite to cultivate cooperation between parents and teachers to provide the necessary support to the child. The majority of hyperactive children in the classroom need some periods of activity, as a result of which they develop some personal relaxation strategies, with the typical example of going out of the classroom for toilet and water. In these cases, it is preferable to prevent the situation, and therefore providing opportunities for hyperactive children to relax outside the room for a short period of time is preferable from causing noise [8].

It is also crucial to inform teachers immediately about the diagnosis of a student with ADHD, as soon as it is received by the respective "Center for Differential Diagnosis of Diagnosis and Support of Special Educational Needs"/KEDDY. It is necessary to inform the teachers in order for them to help the child with ADHD in the educational process through the formation of appropriate learning techniques and the avoidance of incorrect performance behaviors of the child which are differentiated from the other students. Teachers who are called upon to deal with cases of students with this disorder should also be informed about the nature of ADHD, its parameters and the ways it affects a child's learning development, in order to meet the particular learning needs of each student. Finally, it is necessary to inform teachers about the existence of a medication and to perform a specific educational intervention outside the school contexts [14].

At this point it should be mentioned that especially in the case of Greek society, families with children with ADHD are often possessed by guilt as they consider that the occurrence of the disorder is a failure of them. This situation is exacerbated when some members of the social circle make negative comments about the child's performance, further burdening both the child and the family as a whole. Therefore, it is crucial to provide the necessary support and appropriate information from school to parents in order to create a climate of understanding and cooperation within which the child will be able to perform to the maximum, without being emotionally burdened [15]. 
Within the classroom there are two factors through which the necessary help can be offered to children with ADHD, that of the organization of the class and that of the behavior that the teacher adopts. As for the first factor, it is necessary to ensure the creation of an environment within the room that will be reinforcing, paying for features such as comfort, spaciousness, safety and direct eye contact between teacher and students. In particular, children with ADHD should sit in positions that are close to the teacher and at the same time away from the windows, sockets, etc., because due to the impulsiveness and spontaneity of their movements, these children put themselves as well as and their classmates at risk [13].

As for the second factor, once a teacher is asked to help a student with ADHD within his or her class, he or she is required to adopt methods that are completely sterile from characteristics such as mockery, criticism, and negative attitude toward him or her. It is necessary, in collaboration with the other specialists, to clearly clarify the possibilities and weaknesses of the student with ADHD, in order to assign him/her activities that will correspond to them and at the same time will activate his/her motivations. It should also provide these children with activities such as handing out leaflets with exercises, etc., providing them with a form of short-term relaxation, which, as already mentioned, is often sought after. Furthermore, the teacher must reward every effort and every success of these children, reviving their morale and contributing to the development of self-esteem and self-confidence. As for the instructions given to these children, they must be governed by clarity and brevity, because otherwise they may become incomprehensible. Of course, it is necessary to have cooperation and regular meetings between teachers and the child's parents, both to inform them and to create an environment for mobilization and support for the child [6].

As far as parents are concerned, in dealing with a child with ADHD, they must be governed by characteristics such as understanding, support, self-confidence, and adopt a generally positive attitude toward the child. Primarily important for the support of these children is the factor of acceptance of their problem, as it is a given that neither pressure nor punishment can improve the situation. It is important for the parent to fully understand the weaknesses and strengths of their child [8], as well as to provide them with the necessary support and reward in every effort they make. The reward can be offered through the use of verbal and non-verbal means of communication, such as the applause of his efforts, the use of positively charged words, the kiss, the look of applause, the hug, etc. However, it should be noted that every effort should be welcomed regardless of the degree of difficulty. Parental contribution is key to building a child's self-esteem [6].

Then repeating certain activities can be beneficial for a child with ADHD. For example, adopting a morning routine in which a child repeats a series of activities daily forms a program that the child can more easily follow. Furthermore, any kind of encouragement, observation and instruction should be given to the child in a clear and calm manner, free from sarcasm and irony, because other- 
wise the child may perceive them as punishment. One method that is recommended for parents with children with ADHD is that of "time out", the basic principle of which is to offer time to the child in order to calm down and try to control his negative behavior on his own without the outbreak which is extremely effective in young children. Overall, therefore, it becomes clear that parents need to be patient and that in order to help the child they have to make a great effort themselves [2].

\section{Learning Motivations}

\subsection{Definition and Classification}

One of the most important elements in ensuring the essential involvement of a student in educational processes is that of mobilization through the adoption by the teacher of appropriate methods, which will produce incentives that will be inextricably linked to the student's interests. As a concept, motivation is one of the most important factors for learning and ensuring student satisfaction, as in cases where learning motivations disappear, the student does not participate and is excluded from the educational process. The motivator is a part of the psychological world of a person who can achieve the stimulation, direction and maintenance of a particular behavior, leading to the realization of a goal. It therefore becomes clear that providing incentives for students with ADHD is necessary and can contribute to their positive learning and social development [16].

Learning motivations are divided into two main categories, internal motivations and external motivations. In the case of the former, the activity of the individual is carried out by them themselves, without any external remuneration and they have as their origin the voluntary participation of the student in the activities. They are inextricably linked to the factor of the child's inner desire and interest, with the student gaining feelings of enjoyment, satisfaction and fulfillment when he achieves an activity, while at the same time giving value to the efforts and consequently to himself. This specific category of motivation contributes positively to learning, with the result that it becomes necessary to activate it, especially for students with ADHD. The second category of incentives has as its source the existence of external rewards, which can take the form of money, grades, rewards, etc. As a rule, they are provided by someone else, while at the same time there is a risk that the acquisition of rewards will become an end in itself, with the learning process being degraded. Therefore, the teacher is called upon to apply appropriate pedagogical methods to mobilize students intrinsically [17].

According to research, the use of internal motivations is more effective in optimizing a student's participation in learning processes, due to the aforementioned risk involved in mobilizing external motivations. However, in cases where the latter is applied in combination with other practices through which the connection between the child's intrinsic motivations, aspirations and interests is ensured, it may also be beneficial [18]. 


\subsection{Learning Motivations and Students with ADHD}

Two key elements that must be cultivated in the context of the internal mobilization of a student with ADHD are those of autonomy and adequacy [17]. As mentioned above, students with ADHD are characterized by low self-esteem and lack of faith in their abilities due to the difficulties they face. Implanting the concept of autonomy in these students, through the mobilization of their inner motivations, will give them a sense of control over their actions and learning process, ultimately positively affecting their behaviors and dealing with activities. Correspondingly, the concept of competence is associated with a sense of effectiveness and the ability to acquire knowledge, with the result that enhancing it leads to boosting students' self-confidence and enhancing their desire for improvement [18].

Motivation is one of the factors that have significant predictive power in the part of interpreting the differences in behaviors that children with ADHD present. As part of the research, it was found that there is a sensitivity to the motivations of this particular category of students, especially in conditions where they are required to perform a demanding activity and where there is little or no reinforcement [19] [20]. Based on research on the belief system and their motivations, it was concluded that the behavior of children with ADHD has a strong effect on the formation of motivations and especially in areas such as the ineffective regulation of arousal [10], the difficulty in maintaining a certain level of preparedness for action within cancellation situations [21], the efficiency goals they set and their limited sense of self-efficacy [11] [12]. Also, the relationship between adopted behavior and their learning motivations often leads to the existence of low perceptual skills in school contexts, but also in the wider contexts of social skills, in an inadequate self-regulation and concentration on goal pursuit and of course, on the existence of unusually high feedback requirements from these students.

The emergence of a deviant learning process is directly related to the factor of shaping a student's learning motivations, with a two-way relationship as both can act as warning signs of a problem in the other. The cases of students with ADHD have already been reported to have a higher history of failures and greater motivation, resulting in greater sensitivity to the individual elements of a project, such as the degree of difficulty, lack and negative reinforcement and of interest [22].

The majority of students without ADHD usually focus on the activity under solution, while students with this disorder do not focus on the activity, but on other factors such as themselves, i.e. making a fuss, a negative self-assessment, causal performance against them, or others, seeking through their behavior social compliance, recognition, assistance and imitation [22]. These negative self-assessments and help seeking factors have the effect of reducing the chances of these students participating in the learning process. This implies the absence of adequate feedback which ultimately hinders the cultivation of metacognitive skills such as self-monitoring and self-regulation [23]. Therefore, it is necessary 
for the teacher to achieve the gradual cultivation of their learning motivations both internally and externally through feedback, in order for the student to gradually begin to form a sense of control and self-improvement, which will enhance this feeling of their efficiency which due to the difficulties they face has received significant blows [24].

According to research, students with learning disabilities usually differ from their typical classmates in their area of motivation, due to the more negative self-image they form about themselves. The fact that they are governed by a perception based on which they have little or no negative elements, with their basic characteristics being insufficient, compared to the rest, leads to their alienation from the school environment and to the minimization of their internal learning motivations [25].

This negative self-image, combined with weaker self-efficacy beliefs about learning performance, leads to poor performance in learning activities and a lack of interest in the lesson, especially in areas where previous failures have occurred. Also, the cost of a failure is significantly higher for a student's self-esteem with ADHD, compared to a typical student, so the teacher is called upon to identify ways to manage and present each failure [26]. Students with ADHD are characterized by elements such as high procrastination and low self-regulation and self-efficacy, with these elements affecting the sense of self-efficacy and overall self-image, ultimately affecting overall participation and attitude towards learning processes [23].

Regarding external motivations, these are presented to a greater extent to students with ADHD, with their mobilization being more effective through remuneration, praise and punishment, while at the same time this category of students tends to orient their goals based on external motivations such as ratings and praise in order to stimulate a sense of self-efficacy, which in turn leads to increased stress, forming a vicious cycle of reduced performance. Therefore, it is necessary to try to strengthen the internal learning motivations of students with $\mathrm{ADHD}$, in order to reduce their absolute dependence on external factors and their confirmation, although beyond any doubt teachers can contribute to the goal of enhancing students' determination by encouraging comments and recognition of the effort [27]. Also crucial, in addition to adopting strategic educational interventions that will aim to enhance the internally generated self-regulation that leads to the internal mobilization of the individual, it is necessary to form a learning environment in which the student will feel both able to participate and productive [28]. The teacher is asked to form a framework within which the student with ADHD will be able to use his special abilities and at the same time will activate his internal motivations, focusing on his interests. Only in this way is it possible for children with ADHD to develop a more positive attitude towards the learning process, ceasing to be passive through the activation of individual motivations that will lead to the acquisition of pleasure and personal satisfaction from it [27]. 


\subsection{Conclusions on Learning Motivations}

Overall, it is clear that students with ADHD are characterized by a lack of both internal and external learning motivations, adopting an attitude towards learning activities which is characterized by passivity, indifference, but also frustration. The low self-image that they form for themselves, due to the possible failures and difficulties they face, leads to their further alienation from the learning processes, while at the same time it affects in a negative way their general selfesteem and consequently in their entire social life. In this context, their social circle, and especially those involved in their learning process, are called upon to achieve their mobilization and activation of their learning motivations, in order for these students to perform to the maximum extent they can and develop in each field. In order to achieve this, in addition to shaping the appropriate learning contexts and adopting strategies to activate learning motivations, it is necessary to adopt an overall positive attitude towards the disorder and the potential of children with ADHD, which will be governed by patience and support. In order for the child to be led to develop feelings of self-esteem and fulfillment, the corresponding sense of effectiveness and goal achievement must be strengthened, thus making it necessary to provide the necessary reinforcements, applause and praise in every effort the child makes. However, as already mentioned, the declaration of praise should be avoided at all costs in return for substantial success and effectiveness. The goal should be to develop the child's self-regulation and self-assessment skills so that he or she can feel independent and complete, without the exclusive pursuit of third-party affirmation.

\section{Methodology}

\subsection{Method/Approach}

The term method refers to the parameters of the research effort of the researcher, which concern the general methodological approaches, the methods, techniques, means, materials and procedures that he will choose to conduct his research [29]. The present research followed the qualitative methodology which according to Denzin \& Lincoln [30] is a "framed activity" that with research and material practices the researcher is placed in the world and turns it into a series of representations including interviews, conversations, photos and field notes. In other words, researchers examine objects in their natural environment, trying to understand and explain them based on the interpretation given to them by the same people. In addition, according to Merriam [31], qualitative research aims to understand and derive meanings from phenomena that have been observed through the visual perception of participants. The researcher is considered the most basic tool for data collection and retrieval [32]. The present research will be carried out using the qualitative method.

\subsection{Sampling}

The sampling used in the present study is symptomatic sampling. In sympto- 
matic sampling, the individuals are selected by the researcher's environment and these individuals later function as subjects involved and help the research process, until it is possible to obtain the required sample size [33]. The study involved a 9-year-old student with Diagnosed ADHD who is also the subject of the observation, the special educator, the speech therapist, the occupational therapist, the psychologist working with the child as well as the child's mother. The data of the special therapists who participated in the research are summarized in Table 1.

\subsection{Research Tools}

Three research tools were used to collect the data in the present study: the semi-structured interview, the questionnaire and the unstructured observation. The semi-structured interview was used in order for the researcher to be able to gather the necessary data and to directly record the views and experiences of the interviewee [34]. A semi-structured interview was conducted with the experts who participated in this research, consisting of open-ended questions so that participants could answer freely, in their own words. This type of interview provides an opportunity for validity and depth in the respondent's answers [34] [35]. In addition, it is noted that the interviews were conducted individually in a pre-arranged meeting in a neutral environment. More specifically, through the interviews with the Special Educator, the Speech Therapist, the Occupational Therapist and the Psychologist, qualitative data were collected on the ADHD student's Learning Motivations.

In addition, a structured questionnaire with closed-ended questions was used to assess the ability of study participants to effectively mobilize students with disabilities. Respondents had to answer 14 questions with Likert answer scales.

Finally, the research tool of the unstructured observation in the treatment environment of the center where the student receives the supportive treatments with ADHD was utilized. Observational methods for collecting data in research are the specific, empirically substantiated approaches in which the researcher mainly uses his or her senses to collect data about a phenomenon, behavior, or subject.

Table 1. Information about the participants.

\begin{tabular}{|c|c|c|c|c|c|c|}
\hline & Specialty & Sex & Age & $\begin{array}{c}\text { Years of } \\
\text { professional } \\
\text { experience }\end{array}$ & $\begin{array}{c}\text { Vocational } \\
\text { Training Level }\end{array}$ & $\begin{array}{l}\text { Education } \\
\text { in ADHD }\end{array}$ \\
\hline Participant 1 & Psychologist & Female & $40-49$ & $15-20$ & $\begin{array}{l}\text { MA in Special } \\
\text { Education }\end{array}$ & Yes \\
\hline Participant 2 & Special educator & Female & $25-29$ & $1-5$ & $\begin{array}{l}\text { MA in Special } \\
\text { Education }\end{array}$ & Yes \\
\hline Participant 3 & $\begin{array}{l}\text { Occupational } \\
\text { therapist }\end{array}$ & Female & $30-39$ & $5-10$ & Degree & Yes \\
\hline Participant 4 & Speech therapist & Female & $<25$ & $1-5$ & Degree & No \\
\hline
\end{tabular}


The unstructured observation deals with a case where a person examines all aspects of events, situations, issues or phenomena and records data on the problem under investigation without predetermined specifications. The concept of "unstructured" implies that it does not follow the approach of strict control of a list of predefined behaviors as would happen in a structured observation. Instead, observers/researchers using non-structured methods usually enter the "field" without predetermined assumptions about the distinct behaviors they may observe [36]. Through the unstructured observation, information is gathered about the interactions between the child/subject and the environment in which it is located and the effect of the environmental elements on the child can be more easily recorded.

The data collected from the different approaches were analyzed in addition to the triangulation methodology. Triangulation is a general approach that investigates the convergence, complementarity, and asymmetry of results derived from different methodological approaches-or data sources-in relation to the same or related research questions [37]. The choice of this approach lies in the fact that, according to the literature, the validity of the conclusions is reinforced if the different methodological approaches lead to convergent conclusions through triangulation [38].

\subsection{Data Collection Process}

For the implementation of the interviews, we scheduled a pre-arranged meeting at the center with each of the experts who participated in the research. Participants were informed about the purpose of the research, its implementation framework and the process that will follow. Their informed consent was obtained and then the interview process began. Immediately after the interview, the participants were asked to answer the questionnaire with closed-ended questions in order to complete the process of collecting the data concerning the special participants. The interview with the mother of the student with ADHD took place in a separate meeting.

As for observation, it lasted a total of about two months, with a total of $30 \mathrm{ob}-$ servation days, depending on the student's supportive treatment program. Permission was granted by the center as well as the mother's consent for the researcher to attend the various non-participatory supportive therapies. During the observation, notes were kept on the general behavior of the student, his response to therapy/learning and the use of motivation during supportive therapy.

\subsection{Data Analysis}

Thematic analysis was used to analyze the data of the semi-structured interview, as it is a methodology that allows the identification of key issues and patterns in qualitative data [39]. The thematic analysis was judged to be the most appropriate for the present study, as it allowed for the analysis to emerge common or important issues which the participants themselves bring to the 
interview, without guiding the analysis by existing theories or expected issues. According to Clarke and Braun [40], thematic analysis can be used to identify issues in an interview, as well as among participants in relation to their experience, views and perspectives, behavior and practices, allowing a "experiential" research that seeks to understand what participants think, how they feel, and how they behave in relation to the subject under investigation. In order to analyze the data, the interviews were first recorded and then the researcher read the recorded interviews several times, until he became sufficiently familiar with the data. Then, the quality data was coded. Data coding guides the analysis and helps the researcher identify and develop the topics that the participants in the research bring [41]. The coding process was also carried out by a fellow researcher in order to ensure the validity and reliability of the findings. The degree of agreement between the two codifications was high.

\section{Issues of Validity and Reliability}

As with any research, measures have been taken to ensure the maximum validity and reliability of the research. Reliability refers to the consistency with which research produces the same results if repeated, while validity refers to the accuracy or correctness of the findings. In order to strengthen the reliability of the research, the coding of the qualitative data collected from the interviews was repeated by a second researcher and the degree of agreement was satisfactory. The very decision to conduct the research using the triangulation method aims to enhance the validity of the research findings. Furthermore, a significant effort was made to approach the analysis of the qualitative data as impartially and objectively as possible, so as not to affect the validity of the findings from the researcher's personal views and expectations. Detailed methodological planning aims to enhance the external validity and generalizability of the research findings in situations where the same conditions as described in the methodology of the present research apply.

In order to further enhance the validity of the research findings, participants could also evaluate the findings. This practice provides for the recording of interviews with participants as well as the issues identified by the researcher, so that participants can comment on the correctness and suitability of the selection of specific topics. However, due to time constraints on the completion of this research effort, it was not possible to implement this practice.

\section{Issues of Ethics}

This study was conducted in accordance with the ethical limitations of educational research, as proposed by the official guidelines of the British Educational Research Association [42]. According to the rules of ethics, the researcher is obliged to ensure to the participants the right to the protection of their privacy and dignity, by using pseudonyms or code numbers. According to the above, the researcher is obliged to act with respect towards the people involved in the re- 
search study. In order to ensure this, the researcher is obliged to protect the study participants, informing them that a prerequisite for their participation in the research is to ensure their voluntary and fully informed consent, enabling them to withdraw from the study at any time, and of course ensuring the full coverage and protection of their personal data and their information provided on the future.

The research was conducted in a way that ensures the privacy of the participants through confidentiality and anonymity. Anonymity is ensured by the use of specialties instead of names for each participant and no information is included about his or her true identity at the time of recording. Also, all data from the interviews are kept in a secure folder on the researcher's laptop, which is protected by a password. The researcher will not disclose personal data, such as names, personal telephone numbers or addresses to third parties, without first requesting permission from the participants themselves. Before and after the interview, the researcher recalled the context in advance, explained the process and provided all possible clarification to the participants.

Also, the research received moral and ethical approval from the competent committee of the university as well as approval from the institution where the child with ADHD and the student's parents receive treatment. The researcher also guaranteed the physical and mental safety of the participants, and informed that they have the right to withdraw from the investigation at any time deemed necessary. This ensures the integrity of the research [33].

All participants were given an information form describing in detail the purpose of the research, as well as its process. The research protocol gave a complete description of the researcher's personal contact details in order for someone to communicate by participating in case there is a question about the research protocol. Finally, the participants were given a form of consent in order to ensure the signed informed consent of the participants.

\section{Results}

\subsection{Case Study}

The case study includes the intensive, detailed and in-depth study of an individual, a group of individuals or a phenomenon, utilizing various types of content observation and analysis. According to McKernan [43], a wide range of research methods and techniques can be used in the case study. Thus, this research method has the ability to respond to different research fields and research purposes, given its highly flexible nature. Case studies can be divided into different types, such as intrinsic, instrumental, collective and multiple [44].

\subsubsection{Information of the Child}

The case study concerns a 9-year-old student (boy) who has been diagnosed with ADHD and is in the $4^{\text {th }}$ grade of elementary school. The student has been supported for three years in parallel. He is a very active child with several extracurricular activities (basketball, dance and tennis), which, according to his mother, 
also helps with household chores, such as sweeping and mopping. The child's mother assessed the child's level of self-service as quite good (6/7 on a Likert scale) and his ability to handle money with ease a little more than moderate (4/7 on a Likert scale). The mother also stated that the student has very good relations mainly with relatives and did not mention good friendly relations with peers at all.

\subsubsection{Results of Unstructured Observation}

The presentation of the results of the observation is made according to the type of supportive treatment. Initially, the results from the student's support sessions with ADHD with the special educator are reported. In the 15 meetings that were attended in total, it was found that during the interventions of the special educator the student presented with much less frequency ADHD behaviors. The special educator's lessons were quite semi-structured and the use of rewards was also structured, while the student was informed about future rewards before starting any activity.

The course usually included five to six short and varied activities to keep the student interested and not fool around. In language lessons the student's behavior was more structured, with less hyperactive elements. However, when the special educator applied activities and interventions related to the subject of mathematics, the student was obviously more anxious, often complained that he did not like mathematics, got up from his chair and responded much less to motivation than to the language lesson.

During the observation of the student in the occupational therapy sessions, we noticed that the symptoms of ADHD are more evident in the student's behavior in relation to the lessons of the special educator. In particular, in 6 of the 8 sessions of occupational therapy where the observation was made, the student spoke too much, easily lost concentration, was quite impatient to proceed to the next activity. We also noticed that systematic and structured use of motivation was not done, but the student's reward would be given at the end of the session. Probably a factor as to why they're doing so poorly. Only in computer activities did we notice that the student was less upset and anxious, more focused and motivated to do well, probably because working on the computer is something he likes very much. In contrast, with worksheets, he more often said that he was bored and did not want to complete them.

When observing the student in speech therapy sessions, the student's behavior most of the time was relatively better in terms of coordinating attention and controlling his impulsiveness compared to occupational therapy sessions. The speech therapist had organized the program of each meeting in such a way that there were external motivations before each activity, but also explaining to the student the importance of each exercise in relation to his self-image and self-esteem. The student generally seemed to be quite focused, but in several of the sessions he spoke very, very quickly, which made it difficult to complete the exercises successfully. 
Finally, during the observation of the student in the sessions with the psychologist, we noticed that the psychologist has made a reward table and shared it with the student each time before the beginning of the session. The student was informed about the rewards from the beginning of the session and the exact goals they had set, so that the session could take place in a fairly structured environment. This behavioral approach with the reward system seemed to be quite effective for the student. His psychologist reminded him to limit himself when talking fast or talking too much, which seemed to help him a lot.

\subsection{Thematic Analysis Results}

\subsubsection{The Concept of Motivation in Learning}

The first issue approached through the interviews of the experts who participated in the research is the concept of motivation. The interview examined the perceptions of experts on the concept of motivation through different questions, highlighting elements that are important to better understand how different specialties perceive the concept of learning motivations, ways related to learning and how can be used in cases of students with ADHD.

According to the results of the thematic analysis, the views of some experts on the concept of motivation stem from the importance they have for learning. In particular, some experts have almost defined the concept of motivation as an important element for the success of the learning process and did not proceed to more specific definitions. The following excerpts from the interviews provide some relevant answers from experts on what they perceive to be the motivation for learning:

- "Important factor for the cooperation and learning of a child with ADHD". (Psychologist)

- "They can be very important, either internally or externally, and they can raise the level of every child". (Occupational Therapist)

- "An important factor in achieving the goals that everyone has set". (Speech Therapist)

As can be seen from the above excerpts, three of the four experts who participated in the research linked the concept of motivation to the important role it plays in learning, but did not actually describe what motivated them to think. The psychologist mentioned the importance of motivation not only in learning but also in collaboration, which is probably related to the specialty, where motivation is inherently important for the successful cooperation of the psychologist and the client, as without motivation there can be no result through the healing process. The Occupational Therapist on the other hand defines the motivations through the importance they have for the improvement of the child and in combination with their classification internally and externally. This classification is found in the international literature, as mentioned in the theoretical framework, and probably reflects the occupational therapist's professional attitude towards the use of external and internal motivations in a behavioral approach to the treatment of children. Finally, the speech therapist also mentions the importance of 
motivation and links it to the goals set for a child. This approach probably implies that the motivations are necessary to achieve the goals on the one hand because without motivation the child will not work towards the goals on the other hand because when defining the goals, the motivations of the children should be taken into account.

The special educator on the other hand tried to give her own functional definition of the concept of motivation, without using their importance in learning to define them. Specifically, the relevant excerpt from the interview of the special educator is presented below:

- "For me, motivation is a child s pleasure in a structured context". (Special educator)

The special educator describes motivation as a kind of "Positive Aid" that is provided to the child in a structured way in a specific context that results in the child's pleasure. In a way, this answer is a relatively complete illustration of the concept of motivation in learning where the character of motivation is emphasized-something pleasant for the child-and what can be placed-structured context. At the same time, the notion of a structured framework implies a controlled framework, in the sense that motivation in learning should not be considered accidental and conjectural, but as something that is used for a purpose, for some reason and in a controlled way. As mentioned above, this perception is characteristic of the concept of positive reinforcement, which refers to the behavioral model and is widely used to support children with ADHD. However, the special educator does not seem to include in this way the inherent motivations of the child, which may contribute to learning, but not in a structured context.

\subsubsection{The Role of Motivation in Children's Development}

A second issue raised by expert interviews concerns the role of motivation in children's development. As can be seen from the following excerpts, three of the four experts referred to the importance of learning motivations for children's development:

- "Without motivation, there is no evolution". (Psychologist)

- "Without them, there is no progress". (Special educator)

- "Importantly, if there are no incentives, there is no progress". (Occupational Therapist)

The link between motivation and development is clear in all three cases, demonstrating that experts believe that motivation plays a key role in improving a child's skills. This means that in practice, children's motivations should be controlled and re-examined at various stages of treatment or education, so that activities and goals align with them, and when motivation is reduced, appropriate intervention is made for the mobilization of children.

\subsubsection{Motivations and Difficulties in Learning}

An interesting topic that emerged from the interviews and was identified in most of the experts involved in the research is the relationship between motivation and learning difficulties, as shown in the following excerpts: 
- "Motivation is especially important when children have difficulties" (Psychologist)

- "It's important for children to be motivated when something may be difficult for them, whether it's concentration or exercise" (Special Educator)

- "When they have difficulties, it matters what the motivation is". (Occupational Therapist)

- "Especially when the kids are having a hard time, being motivated makes them try harder" (Speech Therapist)

As can be seen above, all four experts who participated in the study converge on the view that motivation is crucial when children have learning difficulties (or the corresponding treatment). The fact that the same view is expressed by four experts in a different field is particularly important, as it shows that motivation is an important factor in better managing difficulties in different situations and different types of intervention. If children have a high level of mobilization and motivation is important to them, then they are more likely to try harder when faced with difficulties or not to give up when something is not at the already acquired level of difficulty or is not in their interests.

\subsubsection{The Motivations of Students with ADHD}

An important issue in this analysis is the motivations that experts believe are effective for students with ADHD. In the incentives, there are convergences between the views of the different experts, especially in terms of the position that the motivations of children with ADHD should be related to their interests, as shown in the following excerpts:

- "In $A D H D$, it is important that the motivations are in accordance with the interest of each child. Along with the interests, I often use the reward chart". (Psychologist)

- "Usually they help a lot of motivation like the game, the reward to do what he wants, to do something he wants or to do something he wants. In general, it is important for ADHD to be motivated by something that the child wants or is interested in". (Special educator)

- "Mostly some reward, encouragement or reward that works as a boost". (Occupational Therapist)

- "It simply came to our notice then. I have worked with children with ADHD who the difference in concentration was very large when the reward was something they really wanted'. (Speech Therapist)

Specifically, three of the four participants clearly stated that the important feature of motivation for children with ADHD is to relate to something they want or something they like. Possibly, even in the case of the fourth participant (Occupational Therapist) where this position of clarity is not stated, the reward as an incentive for children with ADHD concern "exchanges" that are desirable or important for the child. Rewarding is another motivation mentioned by many participants, but it is not clear whether the reward has the meaning of recognition (verbal reward, e.g. "Well done!") or material reward (some sticker) or behavioral (e.g. to play 10 minutes with his favorite game). 
This issue was also highlighted in the ways in which the participants in the research try to strengthen the motivations of children with ADHD.

$>$ "I make a lot of use of the reward but always with a plan, it s important to be structured, to pay attention to the child's behaviors and the goals we have set'. (Psychologist)

$>$ "I don't know; I don't have specific ways but I include the motivations in each child s structured program. Time is of the essence". (Special educator)

$>$ "The main criterion is the interests of each child. I combine the interests of the child with the reward and the protocols". (Occupational Therapist)

"Rewards and rewards that children like, and especially after achieving a goal". (Speech Therapist)

In addition to the need for incentives to fall within the wishes and interests of children in the case of ADHD, three of the four experts referred to the importance of the program for the effectiveness of incentives. For example, the Psychologist explained that in each case, the incentives of each child are included in the program, so that they can be used in a targeted and structured way. In the speech therapist's excerpt, it is even clearer that external mobilization should be combined with achieving a goal. Therefore, experts try to structure the motivations in such a way that they function as factors of positive reinforcement of desired behaviors, while their deprivation is a negative reinforcement of unwanted behaviors. However, it should again be mentioned that the responses of the participants seem to be more about the external motivations ("amplifiers") and not the internal motivations of the students with ADHD.

\subsection{Results of a Structured Questionnaire}

As mentioned in the methodology, the participants were given structured questionnaires in order to evaluate the level at which they believe they can effectively manage a student with learning support needs, such as students with ADHD. According to the results emerged from the questionnaire it seems that the Psychologist seems to believe more that he can effectively manage and mobilize students with special learning needs in most areas and most of the questions asked. In fact, in 10 of the 14 questions he chose the answer "Too much" and in the other four the answer "Very".

A high level of self-efficacy in relation to her ability to effectively manage and successfully motivate students with special learning needs in most areas was also mentioned by the special educator. Specifically, to 6 of his 14 questions, a questionnaire answered "Too much" and to the remaining 8 he answered "Very".

The level of the assessment of the Speech Therapist and the Occupational Therapist is lower. Specifically, the Occupational Therapist who participated in the research answered "a lot" to six of the 14 questions, but in some issues the level of self-assessment was lower. For example, the occupational therapist assessed her ability to adapt questions to the children's level as "Enough", as well as her ability to implement a classroom management system for children with 
learning needs as well as her ability to use alternative learning strategies for children with learning needs. It is possible that the lowest evaluations of the occupational therapist are due to the fact that the questions concern the management skills of students with special needs in a classroom, which is not part of the responsibilities and duties of occupational therapists.

For the same reason, it is possible that the self-assessments of the speech therapist are lower compared to the special educator and the psychologist. In particular, the speech therapist responded that she believes she can manage inappropriate behavior in the classroom with children with learning needs, as well as motivate students with learning needs who show low interest in the lesson. To most questions about learning motivation, the speech therapist answered "enough", while she strongly believes that she can set a different example in something that is difficult for a child with learning disabilities to understand and use a variety of assessment strategies for children with learning disabilities.

\section{Discussion}

The purpose of this research was to investigate the learning motivations of a student with ADHD, through the views of all members of the interdisciplinary team as well as the parent of the student under study but also through the observation of the child himself. Specifically, the research examined the knowledge of the special teaching staff on learning motivations, the factors that they consider to be related to learning motivations, the self-assessment of teachers' efforts to develop student learning motivations with $\mathrm{ADHD}$, the factors that hinder their development of learning motivations and the actions they use to develop the student's learning motivations.

Regarding the first research question, through the semi-structured interviews it was found that the knowledge of the participating experts in relation to learning motivations is targeted and partially limited, in the sense that they mainly referred to the importance and necessity of using external motivations in the form rewards and reinforces, without any reference to the internal motivations and mechanisms through which the motivations contribute to students with ADHD. Two important elements that the specialist therapists and the special educator insisted on were the structured use of motivation and the need for motivation to fall within the wishes and interests of children. The information gathered from the observation process converges with what the participants said in their interviews.

Regarding the second research question, the self-assessment of the experts who participated in the research was carried out using the questionnaire where the participants were placed on the level at which they believe they can develop the motivation of students with ADHD. The psychologist who participated in the research evaluated herself higher than the other educators, which is supported by the data of the observation, where we found that the psychologist made the

most structured and systematic use of techniques to keep the student's motiva- 
tion high. On the other hand, the speech therapist, who had the lowest level of self-esteem in the questionnaire, was found to be much more consistent and systematic in using motivations than she rated herself. In the case of the occupational therapist, there is a discrepancy, since in the observation we found that occupational therapy was the part of the student's treatment in which he presented more ADHD behaviors, was less focused and showed less interest.

Regarding the obstacles in the mobilization of students with ADHD, all participants referred mainly to the difficulty of activities as a barrier factor, emphasizing that better management and greater effort is needed to develop student motivation with ADHD when the latter is faced with more difficult activities. None of the participants in the study mentioned other obstacles that are mentioned in the literature and which concern the very nature of ADHD but also the learning environment and the other characteristics of the intervention.

Finally, with regard to the last research question concerning the actions aimed at developing the student's learning motivation with $\mathrm{ADHD}$, there the participants were limited to answers that were similar to each other, while we would expect greater differences per specialty. In particular, participants reported on the reward table, the child's interests, play, reward, and rewards in general. Here, too, the element of reinforcement and behavioral model is strongly observed. The previous literature refers to the above ways of mobilizing students with ADHD as effective for their learning and functional development, but existing research emphasizes the need for clear construction and the importance of motivating students to be interested.

One way to strengthen the mobilization of students with ADHD that refers to modern research but was not mentioned at all by the participants is to mobilize based on the goals. Since learning objectives are an adaptive form of student mobilization in general, research has shown that combining goals with students 'interests and desires with ADHD is an effective technique to develop students' learning motivations with ADHD.

When examining the academic performance of students with ADHD, frequent and immediate feedback in the form of coherent positive reinforcement programs seems to be extremely successful in maintaining students' learning engagement with ADHD. These strategies have been linked to improving students' self-esteem and learning self-efficacy with ADHD, a motivation that has been found to be important since ADHD students suffer from low levels of learning self-efficacy, and self-esteem [45]. However, the participants in this study did not mention at all the internal motivations of students with ADHD in contrast to the findings of international research that now place great emphasis on the personality and individual characteristics of students with ADHD.

\section{Conclusions}

The purpose of this research was to investigate the learning motivations of a student with ADHD, through the views of all members of the interdisciplinary team as well as the parent of the student under study but also through the ob- 
servation of the child himself. The research questions of the study were partially answered, but not in the depth that the research aimed at, especially in terms of the material of the interviews of the therapists and the special educator.

Overall, it was found that participants do not perceive motivation as a complete and distinct concept, but perceive it through the importance they have for the learning process. In addition, there was only one factor that hindered the motivation, which is the difficulty of the activities that the student is called to complete, while the references to the internal motivations of the students with ADHD are completely absent. From the information of the non-participatory and non-structured observation it was found that the participants in the majority make systematic and structured use of external motivations, which seems to help the students in controlling the behaviors related to ADHD.

Unfortunately, there has been little motivational intervention research with atypical populations, who have greater than normal needs for inoculations against failure [46]. Most research conducted with atypical populations has: a) examined response to immediate failure, b) selected only one population with a disability to compare with typical children, or c) reported descriptive findings of differences in motivation [47] [48]. That is, motivation has not been recognized for its potential to interrupt the spreading of negative effects, although recent evidence suggests that motivation maybe even more important in producing instructional gains for children with poor reading skills than for children with good reading abilities [49]. Others have drawn similar conclusions about the potential of motivational interventions: "It is clear that future attempts to remediate early reading difficulties need to attend to students' reading motivational needs in addition to their reading skill needs" [50].

\section{Restrictions-Limitations}

There are some important limitations to this research. First of all, it should be mentioned that the research is a case study and therefore the generalizability of the findings is not the aim of the research. On the contrary, the aim of the research was to gain a deeper understanding of the perceptions of motivations and ways to enhance learning motivations in an interdisciplinary team working with a student with ADHD. Another limitation is related to the rather short responses of the participants in the interview, which resulted in not collecting enough rich material to conduct the thematic analysis. Furthermore, the fact that the questions in the closed questionnaire referred to classroom conditions may have influenced the participants' responses, as not all participating research experts work in classrooms but in individualized treatment settings at the student support center.

\section{Adding Knowledge to Pre-Existing one}

From the research of the studies and the bibliographic review that was done in the present work, it was observed that there is a quite number of researches that have studied the learning motivations in ADHD. More specifically, this research 
is particularly useful because it concerns the value of learning motivations when it comes to children with ADHD and highlights their importance and contribution in dealing with this kind of disorder. Last but not least, this research enlights a little more the knowledge we have as educators-special or not-as far as learning motivations in ADHD are concerned.

\section{Future Research}

Overall, the findings of this study highlight the need to conduct more large-scale studies in order to better understand how experts can help mobilize students with ADHD. In particular, it is recommended to conduct interventional studies and experimental studies that will help in practice to try techniques and interventions that are not limited to the behavioral model of reinforcement, but also use elements from modern literature that supports the emphasis and internal motivations related to self-efficacy. and the self-image of children with ADHD.

\section{Acknowledgements}

This study would not have been possible without the contribution of numerous people. We would like to thank each and every one of the educational staff who took part in the research.

\section{Conflicts of Interest}

The author declares no conflicts of interest regarding the publication of this paper.

\section{References}

[1] Barkley, R. (1996) Attention Deficit Hyperactivity Disorder. In: Marsh E.J. and Barkley R., Eds., Child Psychology, Guilford Press, New York, 34-67.

[2] Mellor, N. (2009) Attention Deficit/Hyperactivity Disorder or Attention Seeking? Ways of Distinguishing Two Common Childhood Problems. British Journal of Special Education, 36, 26-35. https://doi.org/10.1111/j.1467-8578.2009.00410.x

[3] Cassidy, E., James, A. and Wiggs, L. (2001) The Prevalence of Psychiatric Disorder in Children Attending a School for Pupils with Emotional and Behavioral Difficulties. British Journal of Special Education, 28, 167-173. https://doi.org/10.1111/1467-8527.t01-1-00220

[4] Kakouros, E. and Maniadaki, K. (2000) Attention Deficit Hyperactivity Disorder. Ellinika Grammata, Athens, 45-56.

[5] Humphrey, N. (2009) Including Students with Attention-Deficit/Hyperactivity Disorder in Mainstream Schools. British Journal of Special Education, 36, 19-25. https://doi.org/10.1111/j.1467-8578.2008.00415.x

[6] Holowenko, H. (1999) Attention Deficit/Hyperactivity Disorder. Jessica Kingsley Publishers, London and Philadelphia, 25-34, 37, 111-127.

[7] American Psychiatric Association (2013) Diagnostic and Statistical Manual of Mental Disorders. 5th Edition, Amer Psychiatric Pub. Incorporated, Washington DC. https://doi.org/10.1176/appi.books.9780890425596 
[8] Young, S. and Bramham, J. (2012) Cognitive-Behavioral Therapy for ADHD in Adolescents and Adults: A Psychological Guide to Practice. 2nd Edition, John Wiley \& Sons, 44-56, 67-72, 134-155.

[9] Barkley, R.A. (1997) Behavioral Inhibition, Sustained Attention and Executive Functions: Constructing a Unifying Theory of ADHD. Psychological Bulletin, 121, 65-94. https://doi.org/10.1037/0033-2909.121.1.65

[10] Börger, N., Van der Meere, J., Ronner, A., Alberts, E., Geuze, R. and Bogte, H. (1999) Heart Rate Variability and Sustained Attention in ADHD Children. Journal of Abnormal Child Psychology, 27, 25-33. https://doi.org/10.1023/A:1022610306984

[11] Dunn, P.B. and Shapiro, S.K. (1999) Gender Differences in the Achievement Goal Orientations of ADHD Children. Cognitive Therapy and Research, 23, 327-344. https://doi.org/10.1023/A:1018747716137

[12] Antoniou, A.S., Geralexis, I. and Charitaki, G. (2017) Special Educators' Teaching Self-Efficacy Determination: A Quantitative Approach. Psychology, 8, 1642-1656. https://doi.org/10.4236/psych.2017.811108

[13] Cornoldi, C., Meo, T.D., Offredi, F. and Vio, C. (2001) ADHD a scuola. Strategie efficaci per gli insegnanti. Erickson, Italy, 56-78.

[14] Kalantzi-Azizi, A. and Zafeiropoulou, M. (2004) School Adaptation: Learning and Coping. Ellinika Grammata, Athens, 59-78.

[15] Varvogli, L. (2005) What Happens to the Child? Kastanioti, Athens, 45-61.

[16] Hidi, S. and Renninger, K.A. (2006) The Four-Phase Model of Interest Development. Educational Psychologist, 41, 111-127. https://doi.org/10.1207/s15326985ep4102 4

[17] Deci, E.L. and Ryan, R.M. (2000) The "What" and "Why" of Goal Pursuits: Human Needs and the Self-Determination of Behavior. Psychological Inquiry, 11, 227-268. https://doi.org/10.1207/S15327965PLI1104 01

[18] Ferreira, M., Cardoso, P.A. and Abrantes, J.L. (2011) Motivation and Relationship of the Student with the School as Factors Involved in the Perceived Learning. Procedia-Social and Behavioral Sciences, 29, 1707-1714. https://doi.org/10.1016/j.sbspro.2011.11.416

[19] Sarikaya, İ., Töman, U. and Öztürk, M. (2018) Examining the Variables Predicting Attitudes towards Teaching Profession of Preservice Classroom Teachers. Acta Didactica Napocensia, 11, 129-141. https://doi.org/10.24193/adn.11.1.10

[20] Carlson, C.L. and Tamm, L. (2000) Responsiveness of Children with Attention Deficit Hyperactivity Disorder to Reward and Response Cost: Differential Impact on Performance and Motivation. Journal of Consulting and Clinical Psychology, 68, 73-83. https://doi.org/10.1037/0022-006X.68.1.73

[21] Richer, J. (1993) Avoidance Behavior, Attachment and Motivational Conflict. Early Child Development and Care, 96, 7-18. https://doi.org/10.1080/0300443930960102

[22] Vauras, M. (1998) Resistance to Treatment-Working with Motivationally Highly Vulnerable Students with Learning Problems. In: Kostaridou-Eucleidi, A., Ed., The motivations in Education, Ellinika Grammata, Athens, 78-90.

[23] Panteliadou, S. (2010) Learning Disabilities and Educational Practice: What and Why. Ellinika Grammata, Athens, 67-78.

[24] Bandura, A. (1989) Human Agency in Social Cognitive Theory. American Psychologist, 44, 1175-1184. https://doi.org/10.1037/0003-066X.44.9.1175

[25] Bender, W.N. and Wall, M.E. (1994) Social-Emotional Development of Students with Learning Disabilities. Learning Disability Quarterly, 17, 323-341. https://doi.org/10.2307/1511128 
[26] Schunk, D. (1990) Self-Efficacy and Cognitive Achievement: Implications for Students with Learning Problems. In: Torgesen, K.J., Ed., Cognitive and Behavioral Characteristics of Children with Learning Disabilities, PROED, Austin, 139-158.

[27] Panteliadou, S., Patsiodimou, A. and Botsas, G. (2004) Learning Difficulties in Secondary Education. University of Thessaly, Pedagogical Department of Special Education, Volos, 109-134.

[28] Charitaki, G., Soulis, S.G. and Tyropoli, R. (2019) Academic Self-Regulation in Autism Spectrum Disorder: A Principal Components Analysis. International Journal of Disability, Development and Education, 1-20. https://doi.org/10.1080/1034912X.2019.1640353

[29] Dimitropoulos, G.E. (2002) Educational Evaluation-The Evaluation of Education and Educational Work. Grigoris, Athens.

[30] Denzin, N.K. and Lincoln, Y.S., Eds. (1994) Handbook of Qualitative Research. Sage, Thousand Oaks, CA.

[31] Merriam, S.B. (1998) Qualitative Research and Case Study Applications in Education. 2nd Edition, Jossey-Bass, San Francisco.

[32] Cohen, L. and Manion, L. (1994) Educational Research Methodology. Metaichmio, Athens. (Translation: Mitsopoulou, X. and Filopoulou, M.)

[33] Cohen, L., Manion, L. and Morison, K. (2008) Educational Research Methodology. 1st Edition, Metaichmio, Athens.

[34] Karageorgos, D. (2002) Research Methodology in the Sciences of Education-A Didactic Approach. Savvalas, Athens.

[35] Bania, T.A., Antoniou, A.S., Theodoritsi, M., Theodoritsi, I., Charitaki, G. and Billis, E. (2019) The Interaction with Disabled Persons Scale: Translation and Cross-Cultural Validation into Greek. Disability and Rehabilitation, 1-8. https://doi.org/10.1080/09638288.2019.1643420

[36] Mulhall, A. (1998) Methods of Data Collection for Quantitative Research. In: Roe, B. and Webb, C., Eds., Research and Development in Clinical Nursing Practice, Whurr Publishers, London, 135-169. https://doi.org/10.1002/9780470699270.ch8

[37] Olsen, W.K. and Morgan, J. (2004) A Critical Epistemology of Analytical Statistics. Conference Paper, The British Sociological Association, York.

[38] Moran-Ellis, J., Alexander, V.D., Cronin, A., Dickinson, M., Fielding, J., Sleney, J. and Thomas, H. (2004) Following a Thread-An Approach to Integrating Multi-Method Data Sets. Paper Given at ESRC Research Methods Programme, Methods Festival Conference, Oxford.

[39] Braun, V. and Clarke, V. (2006) Using Thematic Analysis in Psychology. Qualitative Research in Psychology, 3, 77-101. https://doi.org/10.1191/1478088706qp063oa

[40] Clarke, V. and Braun, V. (2014) Thematic Analysis. In: Teo, T., Ed., Encyclopedia of Critical Psychology, Springer, New York, 1947-1952. https://doi.org/10.1007/978-1-4614-5583-7 311

[41] Braun, V., Clarke, V. and Rance, N. (2014) How to Use Thematic Analysis with Interview Data (Process Research). In: Vossler, A. and Moller, N., Eds., The Counselling \& Psychotherapy Research Handbook, Sage, London, 183-197.

[42] BERA (British Educational Research Association) (2011) Ethical Guidelines for Educational Research. http://www.bera.ac.uk/publications/Ethical\%20Guidelines

[43] McKernan, J. (1996) Curriculum Action Research: A Handbook of Methods for the Reflective Practitioners. Kogan Page, London.

[44] Stake, R. (1995) The Art of Case Study Research. Sage, London. 
[45] Du Paul, G.J., Jitendra, A.K., Volpe, R.J., Tresco, K.E., Lutz, J.G., Vile Junod, R.E., et al. (2006) Consultation-Based Academic Interventions for Children with ADHD: Effects on Reading and Mathematics Achievement. Journal of Abnormal Child Psychology, 34, 633-646. https://doi.org/10.1007/s10802-006-9046-7

[46] Sideridis, G., Mouzaki, A., Simons, P. and Protopapas, A. (2006) Classification of Students with Reading Comprehension Difficulties: The Roles of Motivation, Affect, and Psychopathology. Learning Disability Quarterly, 29, 159-180.

https://doi.org/10.2307/30035505

[47] Lee, J. and Zentall, S.S. (2012) Motivational Differences among Students with At-Risk for Reading Disabilities, ADHD, Combined Groups, and Typical Comparisons. Manuscript Submitted for Publication.

[48] Zentall, S.S. and Beike, S. (2012) Achievement and Social Goals of Younger and Older Elementary Students: Response to Academic and Social Failure. Learning Disability Quarterly, 35, 39-53. https://doi.org/10.1177/0731948711429009

[49] Logan, S., Medford, E. and Hughes, N. (2011) The Importance of Intrinsic Motivation for High and Low Ability Readers Reading Comprehension Performance. Learning and Individual Differences, 21, 124-128. https://doi.org/10.1016/j.lindif.2010.09.011

[50] Quirk, M., Schwanenflugel, P.J. and Webb, M. (2009) A Short-Term Longitudinal Study of the Relationship Between Motivation to Read and Reading Fluency Skill in Second Grade. Journal of Literacy Research, 41, 196-227. https://doi.org/10.1080/10862960902908467 